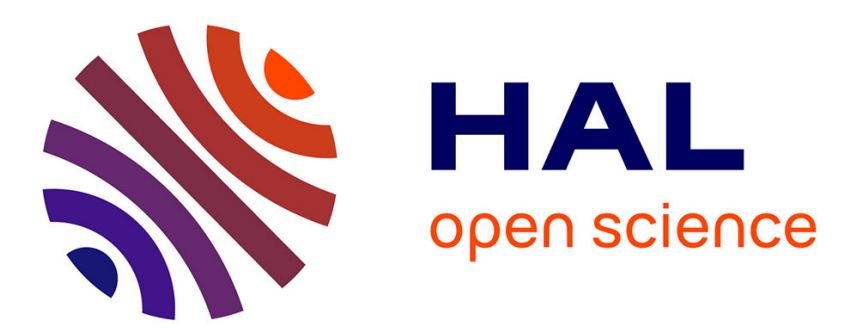

\title{
Electrochemical Properties of Model Compounds of Nicotinamide-adenine-dinucleotide in Aqueous Solution
}

Daniel R. Thevenot, Gilbert Hammouya

\section{To cite this version:}

Daniel R. Thevenot, Gilbert Hammouya. Electrochemical Properties of Model Compounds of Nicotinamide-adenine-dinucleotide in Aqueous Solution. Biological Aspects of ElectrochemistryExperientia Suppl., 18, pp.631 - 645, 1971. hal-01096351

\section{HAL Id: hal-01096351 \\ https://hal-enpc.archives-ouvertes.fr/hal-01096351}

Submitted on 17 Dec 2014

HAL is a multi-disciplinary open access archive for the deposit and dissemination of scientific research documents, whether they are published or not. The documents may come from teaching and research institutions in France or abroad, or from public or private research centers.
L'archive ouverte pluridisciplinaire HAL, est destinée au dépôt et à la diffusion de documents scientifiques de niveau recherche, publiés ou non, émanant des établissements d'enseignement et de recherche français ou étrangers, des laboratoires publics ou privés.

\section{(c)(1)}

Distributed under a Creative Commons Attribution| 4.0 International License 


\section{Electrochemical Properties of Model Compounds of Nicotinamide-adenine-dinucleotide in Aqueous Solution}

by D. ThÉVEnot and G. Hammouya

Laboratoire d'Energétique Electrochimique, 10 rue Vauquelin, 75 Université Paris VI, Paris 5, France

\section{Summary}

The reduction behavior of $\mathrm{N}_{1}$-methyl nicotinamide iodide has been studied by drop-time controlled polarography. In highly acidic media (below $\mathrm{pH}$ 3) two $\mathrm{pH}$ dependent waves were observed (I and $\mathrm{I}^{\prime}$ ) the latter having an abnormally high limiting current. In the $\mathrm{pH}$ range of 3-10, two waves were observed (II and III), the former being $\mathrm{pH}$-independent whereas the $E_{1 / 2}$ of the latter shifted $-60 \mathrm{mV}$ per $\mathrm{pH}$ unit. Evidence is presented for a chemical association step, possibly a dimerization occurring between reduction steps II and III. Reoxidation of the reduction product of wave II was obtained at $740 \mathrm{mV}$ above the potential of the wave II by cyclic voltammetry on stationary vitreous carbon electrodes. This reoxidation peak is also $\mathrm{pH}$ independent.

\section{Introduction}

The pyridine coenzymes nicotinamide mononucleotide $\left(\mathrm{NMN}^{+}\right)$, nicotinamide adenine dinucleotide $\left(\mathrm{NAD}^{+}\right)$and nicotinamide-adenine-dinucleotide phosphate $\left(\mathrm{NADP}^{+}\right)$(Fig. 1), play a prominent part in biological oxido-

Fig. 1.

Formulas of pyridine nucleotides.

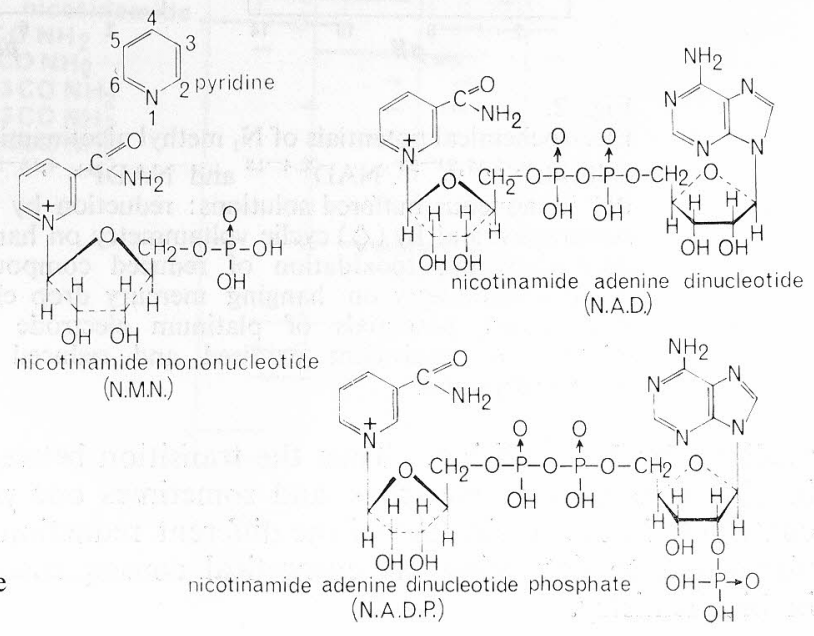


reduction reactions. They participate in a large number of enzymatic reactions in which they undergo a two-electron one-proton reduction to form corresponding reduced forms NMNH, NADH and NADPH. In the electron-transport chain $\mathrm{NAD}^{+}$and $\mathrm{NADP}^{+}$are reduced by substrates (alcohols, aldehydes ... $)^{1}$ and then reoxidized by riboflavin containing compounds (FMN, FAD, FADP) which are known to form stable semiquinone inter-
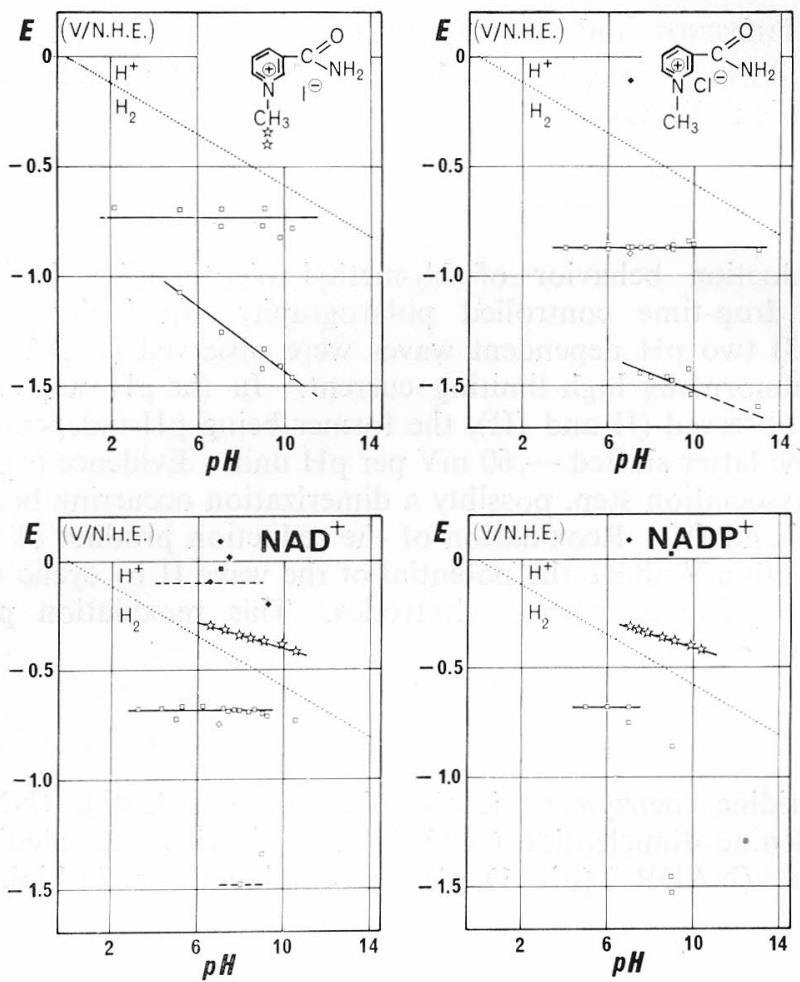

Fig. 2.

Electrochemical potentials of $\mathrm{N}_{1}$ methyl nicotinamide iodide and chloride ${ }^{9,13,17,21-23}, \mathrm{NAD}^{+4^{4-13}}$ and $\mathrm{NADP}^{+}{ }^{4,13-20}$ at different $\mathrm{PH}$ in aqueous buffered solutions: reduction by $(\square)$ d.c. polarography, and by $(\diamond)$ cyclic voltammetry on hanging mercury drop electrode; reoxidation of reduced compounds by ( ) cyclic voltammetry on hanging mercury drop electrode; (s) zero-current potentials of platinum electrode immersed in mixtures of equivalent oxidised and reduced forms of the same compound.

mediates by 1 e addition. Thus the transition between $\mathrm{NAD}^{+}$and $\mathrm{NADH}$ involve one or two electrons and sometimes one proton. Our aim is to contribute in the elucidation of the different reduction and oxidation mechanisms and to determine the energetical consequences of these mechanisms in biochemistry. 
Pyridine derivatives have been more or less extensively studied for their oxido-reduction properties. With the most common substituents $\left(-\mathrm{CO}_{2} \mathrm{H}\right.$, $\left.-\mathrm{CO} \mathrm{CH}_{3},-\mathrm{CONH}_{2},-\mathrm{CHO},-\mathrm{CN},-\mathrm{NO}_{2}, \ldots\right)$ they are not usually oxidable but can be reduced on a mercury electrode (Table 1). By com-

Table 1. $\mathrm{pH}$ range used in electrochemical study of pyridine derivatives: reduction shown as possible (- ${ }^{-}$and impossible $(---)$, oxidation shown as possible $(=)$ and impossible $(===)$. $(\diamond) \mathrm{p} K_{a}$ values of these compounds in aqueous solution at room temperature ${ }^{33-35}$.

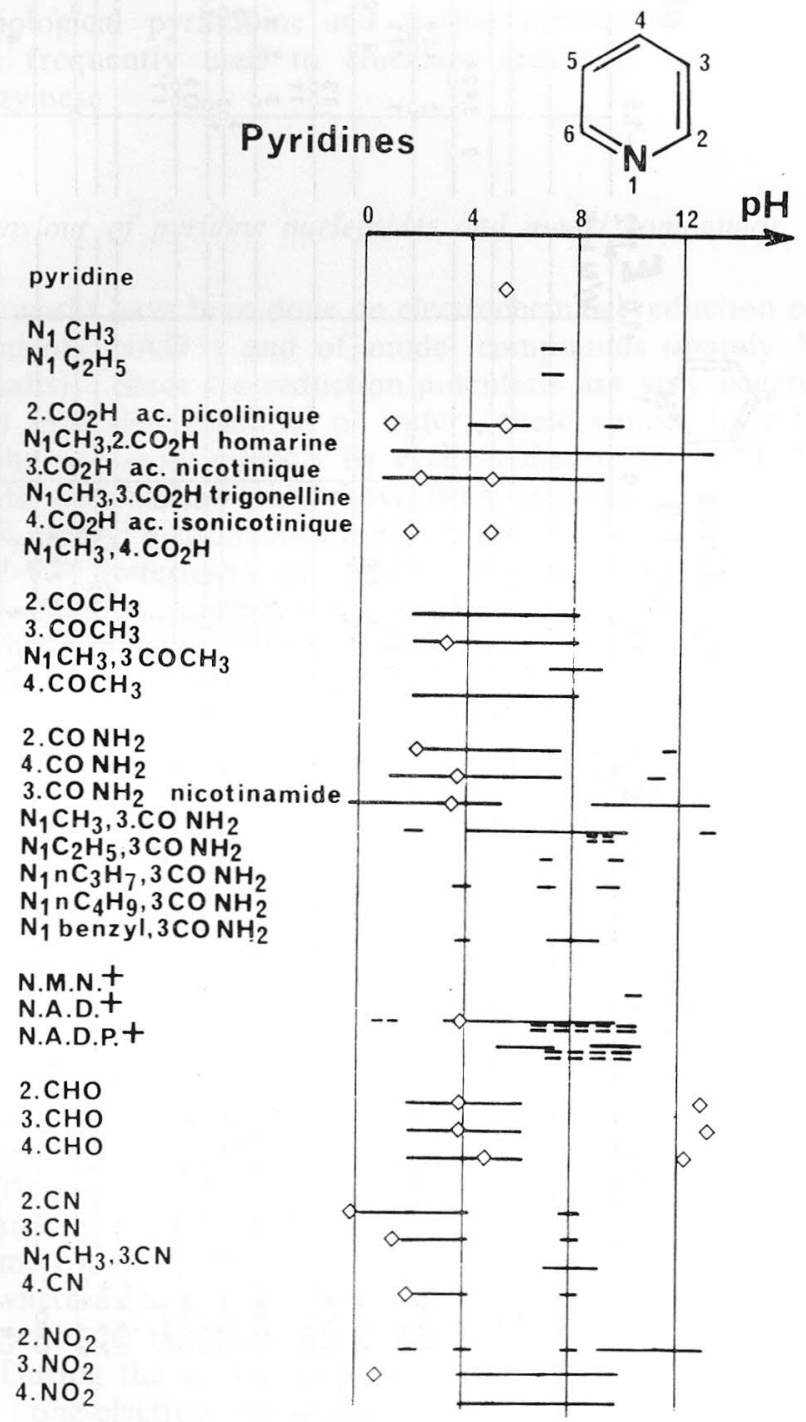


Table 2. Electrochemical potentials of pyridine derivatives in aqueous solution at room temperature: effect of nature and position of the simplest substituents. Reduction is observed by $(\square)$ d.c. polarography, cyclic voltammetry on $(\Delta)$ hanging mercury drop electrode; reoxidation is observed by cyclic voltammetry on ( hanging mercury drop or (*) platinium electrodes. Mixtures of oxidized and reduced forms of the same derivatives give (s) zero-current normal potentials.

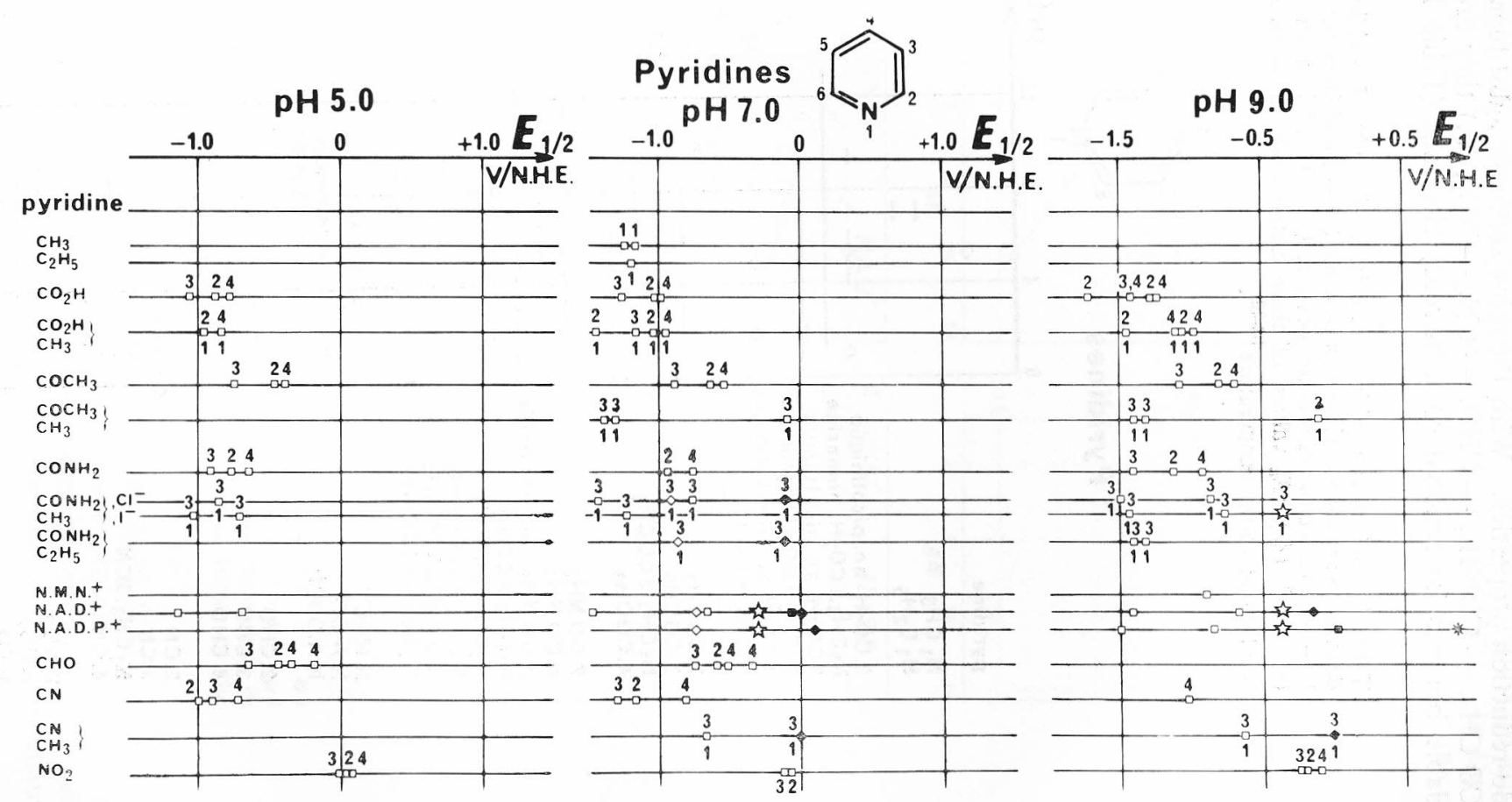


parison of the half-wave potentials at a given $\mathrm{pH}$ (Table 2) one gets a good idea of the influence of the substituents nature and position: $-\mathrm{NO}_{2},-\mathrm{CHO}$, $-\mathrm{COCH}_{3}$, and $-\mathrm{CONH}_{2}$ are the most powerfull substituents in shifting the $E_{1 / 2}$ to a less negative potential. This effect is enhanced by quaternisation of the pyridine nitrogen: for neutral media for example, nicotinamide was shown to be reduced at -1.22 (N.H.E.) ${ }^{2}$ wheras $\mathrm{N}_{1}$ methyl nicotinamide iodide is reduced at - 0.85 N.H.E. Thus a good model compound of $\mathrm{NMN}^{+}$, $\mathrm{NAD}^{+}$and NA.DP ${ }^{+}$contains the nicotinamide ring in conjunction with at least a simple aliphatic chain to replace the complex ribose-pyrophosphate-adenine moiety. Just as pyrimidine is used as a model compound for biological pyrimidine and purine derivatives ${ }^{3}, \mathrm{~N}_{1}$ alkyl nicotinamides are frequently used to elucidate reduction or reoxidation of pyridine coenzymes.

\section{Reduction behaviour of pyridine nucleotides and model compounds}

Extensive works have been done on electrochemical reduction of pyridine nucleotides (mainly $\mathrm{NAD}^{+}$) and of model compounds (mainly $\mathrm{N}_{\mathbf{j}}$ methyl nicotinamide salts). Since the reduction potentials are very negative (below the theoretical reduction potential of water), these studies have been done by polarography and more recently by cyclic voltammetry on D.M.E. Experimental data obtained in water have been examined and are presented on Fig. 2 for $\mathrm{N}_{1}$ methyl nicotinamide iodide and chloride ${ }^{9,13,17,21-23} \mathrm{NAD}^{+4-13}$ and $\mathrm{NADP}^{+4,13-20}$ [references on $\mathrm{NMN}^{+}$are very rare $\left.{ }^{4}\right]$. The addition of controlled potential electrolysis together with U.V. spectroscopy and isolation of reduction products give similar results and identical interpretation for all these pyridine nucleotides. In neutral or basic media (when reduced pyridine nucleotides are the most stable) electrochemical reduction is done in two steps. During the first step a simple one electron transfer gives a radical which is supposed to dimerize ${ }^{36}$ :

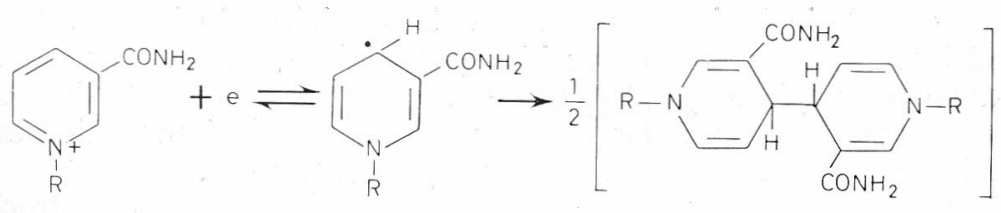

The dimerization rate was determined by variation of the $E_{1 / 2}$ with the sweep rate ${ }^{13}$ and by pulse radiolysis ${ }^{24}$ : the data corresponding to NAD are of the same order of magnitude $\left(8.5 \times 10^{6}\right.$ and $5.6 \times 10^{7} 1 \mathrm{~mole}^{-1} \mathrm{~s}^{-1}$ respectively) whereas those obtained with $\mathrm{N}_{1}$ methyl nicotinamide salts are very different with the two methods $\left(2.2 \times 10^{-2}\right.$ and $6.9 \times 10^{7} 1 \mathrm{~mole}^{-1} \mathrm{~s}^{-1}$ respectively). During the second step two reactions are said to occur simultanously: the one-electron one-proton reduction of the radical formed 
during the first step and the two-electrons two-protons reduction of the dimer:

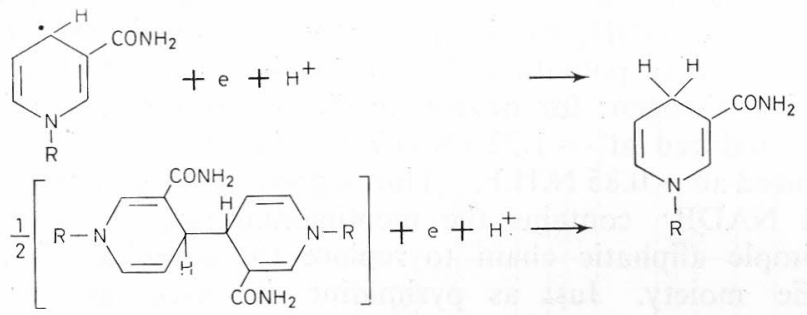

According to enzymatic and U.V. spectroscopic data both reactions give a product identical to $\mathrm{NADH}$ or its model compounds i.e. the 1.4-dihydroisomer. Electrolysis at the second step potential do not gives usually very high yields of $\mathrm{NADH}^{11}$ but strangely gives higher yields of NADPH $(95 \%$ under conditions were $50 \% \mathrm{NADH}$ was obtained) and of $\mathrm{N}_{1}$ methyl nicotinamide dihydro-derivative. The competition between the two second step reduction reactions and their respective rates are not yet well defined.

Fig. 2 illustrates the identity of behaviour of $\mathrm{NAD}^{+}$and $\mathrm{NADP}^{+}$and their similitude with the $\mathrm{N}_{1}$ methyl nicotinamide salts behaviour: the latter compounds present $E_{1 / 2}$ shifted of 50 to $100 \mathrm{mV}$ towards more negative potentials.

\section{Oxidation behaviour of reduced pyridine nucleotides and model compounds}

Most of the previous electrochemical investigations have been restricted largely to the reduction of $\mathrm{NAD}^{+}, \mathrm{NADP}^{+}$and their analogs. Incidentaly they have noted some electrochemical characteristics of the different reduced forms. The 1 e reduced form (radical) has a very short lifetime [some milliseconds ${ }^{13}$ ] and can be reoxidized at a potential very near to that of the reduction potential (reversible electron transfer). The dimerization product of this radical is fairly stable and is reoxidized in $\mathrm{NAD}^{+}, \mathrm{NADP}^{+}$or model compounds at a potential ranging between -0.1 and $+0.1 \mathrm{~V}$ versus N.H.E. in neutral media (Fig. 2). NADH, NADPH or model compounds are also fairly stable in basic media and can be reoxidized in $\mathrm{NAD}^{+}, \mathrm{NADP}^{+}$ or model compounds at very positive potentials $(+0.86 \mathrm{~V}$ versus N.H.E. for NADPH at $\mathrm{pH} 9^{20}$ ). The $\mathrm{pH}$ and compound concentration range of these studies were not large enough to give useful information on the mechanism energetics of the electron and proton transfer.

Very recently HAAS ${ }^{25}$ reported a more extensive study on electrochemical oxidation of NA.DH analogs in acetonitrile. The compounds named RNH are: $1-$ (2.6-dichlorobenzyl) - 1, 4 dihydronicotinamide, 1-methyl 1,4 dihydronicotinamide, $1 n$-propyl -1.4 dihydronicotinamide and 1-benzyl 1,4 dihydronicotinamide. Using cyclic voltammetry on platinium and carbon electrodes, this author presents experimental evidence for the formation in the first step of a protonated pyridinyl radical $\left(\mathrm{RNH}^{+}\right)$by one electron transfer reaction:

$$
\mathrm{RNH} \rightarrow \mathrm{RNH}^{+}+1 \mathrm{e}
$$


This protonated radical $\mathrm{RNH}^{\cdot+}$ undergoes one or more additional reactions involving proton or electron transfer, depending on conditions. In the absence of base in aprotic acetonitrile the $\mathrm{RNH}^{+}+$disproportionates to form the oxidized product pyridinium salt $\left(\mathrm{RN}^{+}\right)$and the protonated form of the substrate $\left[\mathrm{H}(\mathrm{RNH})^{+}\right]$which undergoes further chemical reactions to give different products:

$$
2 \mathrm{RNH}^{+} \rightarrow \mathrm{RN}^{+}+\mathrm{H}(\mathrm{RNH})^{+}
$$

In the presence of base, the protonated pyridinyl radical intermediate $\mathrm{RNH}^{+}+$reacts to form the pyridinyl radical (RN·) which undergoes immediate electrochemical oxidation to $\mathrm{RN}^{+}$:

$$
\mathrm{RN} \cdot \rightleftharpoons \mathrm{RN}^{+}+\mathrm{e}
$$

Experimental results clearly exclude oxidation of RNH by a two electron mechanism.

\section{Potentiometric behaviour of mixtures of $\mathrm{NAD}^{+}$and $\mathrm{NADH}$ or of model com- pounds}

The potentiometric behaviour of mixtures of oxidized and reduced forms of the same pyridine nucleotide or model compounds, is well known and dates back to the thirties with the work of KARRER ${ }^{22,23}$. This author elucidated the non-enzymic reduction of $\mathrm{NAD}^{+}$using simple $\mathrm{N}_{\mathbf{1}}$ alkyl nicotinamides as $\mathrm{N}_{1}$ methyl nicotinamide iodide and chloride and $\mathrm{S}_{2} \mathrm{O}_{4}^{2-}$ as powerful reducer. More recently LEACH et al. ${ }^{26}$ developped a similar potentiometric study and illustrated the important role of redox mediators (i.e. redox systems of similar normal potential such as rosinduline $2 \mathrm{G}$ or benzyl viologen) for the stability of the electrode potential. The important fact to be noted is the situation of this potential regarding to the reduction and to the oxidation potentials. As illustrated by Fig. 2, the potentiometric data obtained are all situated above the theoretical reduction potential of water and about at half-way between the electrochemical $E_{1 / 2}$ of formation of the dimer (first reduction step) and of its oxidation (first reoxidation step).

The $\mathrm{pH}$-dependance of the zero-current potential of mixtures of $\mathrm{NAD}^{+}$$\mathrm{NADH}^{6}$ and of $\mathrm{NADP}^{+}-\mathrm{NADPH}^{16}$ gives the same overall mechanism:

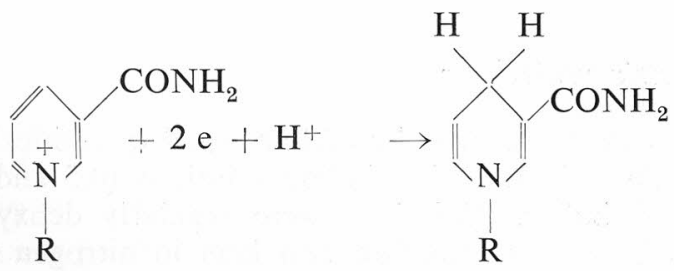

the normal potential decreasing of $30 \mathrm{mV}$ per $\mathrm{pH}$ unit. 


\section{Conclusion}

The knowledge of the different reduction and oxidation mechanisms of pyridine nucleotides will obviously bring interesting informations for the elucidation of their biochemical role in the respiratory chain. This knowledge includes the explanation of the discrepancies between the reduction, oxidation, and zero-current potentials of these compounds. Most important energetic and kinetic information should come from these discrepancy studies.

\section{Experimental}

\section{Reagents}

Buffer solutions were prepared from chemicals of analytical reagent grade at a concentration at least 50 times greater than those of compound examined (usually $0.5 \mathrm{M}$ acidic and $0.5 \mathrm{M}$ basic form). Following buffers were used: chloride, phosphate (first and second $\mathrm{p} K_{a}$ ), glycine (first and second $\mathrm{p} K_{a}$ ), formate, acetate, imidazole, tris, borate (first $\mathrm{p} K_{a}$ ), carbonate (second $\mathrm{p} K_{a}$ ) and potassium hydroxide.

$\mathrm{N}_{1}$ methyl nicotinamide iodide (SIGMA and $\mathrm{K}$. and $\mathrm{K}$ ) was purum grade; its polarographic pattern gave no evidence of any electroactive impurity.

\section{Apparatus}

Triangular potential sweep voltammetry (cyclic voltammetry) was carried out with different TACUSSEL apparatures (PRT 20-2X, GSTP, two ADTP) and a TeKTROnix R 564 B storage oscilloscope.

Direct current polarography was carried out with different TACUSSEL apparatuses (PRT 500 LC, Servovit 9 B, S6RZ) and a Sefram XY bigalvanometric recorder.

A conventional thermostated three electrode cell of $15 \mathrm{~cm}^{3}$ was em ployed. The D.M.E. was synchronized with the potential sweep by a TACUSSEL electrical hammer (MPO animated by a GCMR). For d.c. polarography the drop-time was regulated at $0.5 \mathrm{~s}$ thus eliminating the erratic variations of drop-time at very negative potentials or the use of Desicote or related products.

\section{General voltammetric procedures}

Test solutions were prepared by adding small quantities of highly concentrated $\mathrm{N}_{1}$ methyl nicotinamide iodide solutions $(0.5$ and $0.05 M)$ to a known volume of buffer. Solutions were regularly deoxygenated for at least 15 minutes before examination and kept in nitrogen atmosphere.

For d.c. polarography, the potential was allowed to change at a rate of $0.25 \mathrm{~V} / \mathrm{min}$, the highest sweep rate allowed by the XY recorder used. 
Although an $\mathrm{Ag}|\mathrm{AgCl}|$ saturated $\mathrm{KCl}$ reference electrode was used, all potentials cited are referred to the N.H.E. at $25.0 \pm 0.2^{\circ} \mathrm{C}$, temperature of the thermostated cell.

\section{Results}

Polarographic behaviour of $N_{1}$ methyl nicotinamide iodide in dilute aqueous solutions

Wave pattern

Over the 0.6 to $9.6 \mathrm{pH}$ range, $\mathrm{N}_{1}$ methyl nicotinamide iodide in dilute aqueous solution $\left(10^{-4} M\right)$ gives four polarographic waves (Fig. 3). At low $\mathrm{pH}$ two $\mathrm{pH}$-dependent waves (waves $\mathrm{I}$ and $\mathrm{I}^{\prime}$ ) are shown, the second one

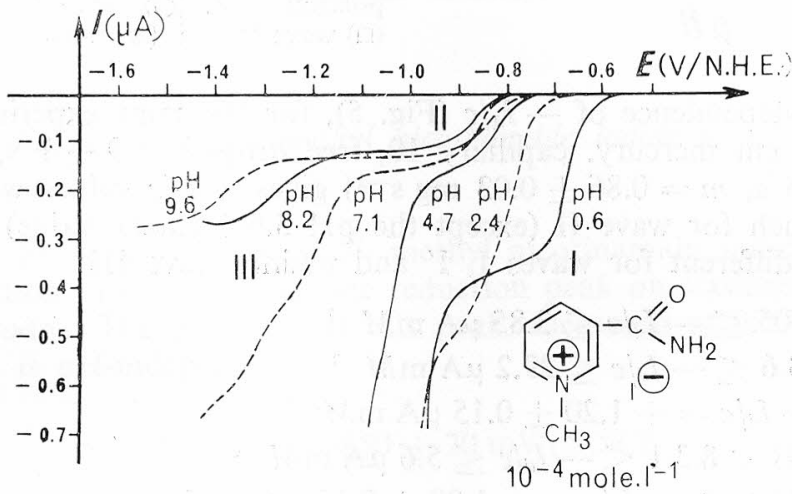

Fig. 3.

Reduction of $10^{-4} M$ aqueous solutions of $\mathrm{N}_{1}$ methyl nicotinamide iodide by drop-time controlled polarography: $\mathrm{pH} 0.56$ ( $\mathrm{HCl}$ ), 2.41 (glycine), 4.68 (acetate), 7.15 (imidazole), 8.25 (tris) and 9.57 (borate).

being about 10 times higher than the first. At about $\mathrm{pH} 3.0$ wave I splits into two waves (waves II and III) whereas wave I' disappears in the background. The wave II is $\mathrm{pH}$-independent and its limiting current is about the half of wave I. The wave III is pH-dependent and its limiting current show large and erratic values if the $\mathrm{pH}$ is below 8.0. Above this $\mathrm{pH} 8.0$ waves II and III present the same limiting current.

The $\mathrm{pH}$-dependence of $E_{1 / 2}$ (Fig. 4) gives the following $E_{1 / 2}$ versus $\mathrm{pH}$ linear relationships at this $\mathrm{N}_{1}$ methyl nicotinamide iodide concentration $\left(10^{-4} M\right)$ :

Wave I $: E_{1 / 2}=[-633-76 \mathrm{pH}] \pm 10 \mathrm{mV}$ (N.H.E.)

Wave I' $: E_{1 / 2}=[-970-45 \mathrm{pH}] \pm 10 \mathrm{mV}$ (N.H.E.)

Wave II : $E_{1 / 2}=-830 \pm 25 \mathrm{mV}$ (N.H.E.)

Wave III : $E_{1 / 2}=[-690-70 \mathrm{pH}] \pm 30 \mathrm{mV}$ (N.H.E.)

Wave III gives an exceptional high value for its $E_{1 / 2}(130 \mathrm{mV}$ above the linear relationship) in glycine buffer ( $\mathrm{pH}$ 9.94). 


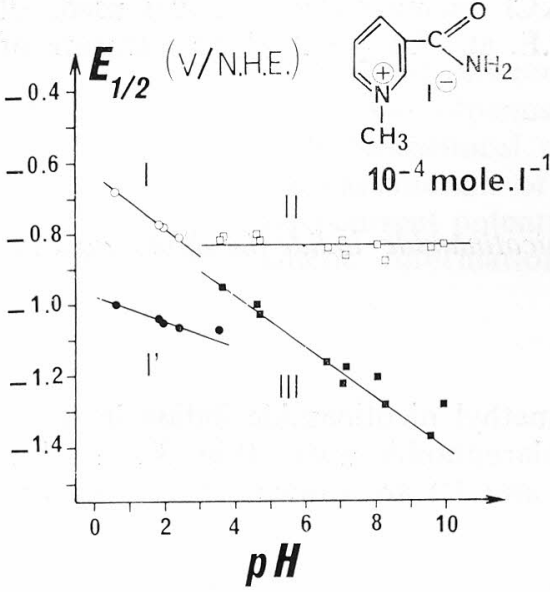

Fig. 4.

Diagram $E_{1 / 2}$ versus $\mathrm{pH}$ for the reduction of $10^{-4} M$ aqueous solutions of $\mathrm{N}_{1}$ methyl nicotinamide iodide by drop-time controlled polarography: (O) wave I, (๑) wave $I^{\prime}$, ( $\square$ ) wave II and ( $)$ wave III.

The $\mathrm{pH}$-dependence of $-I_{\mathrm{d}} / c$ (Fig. 5), for the same experimental conditions $(35.0 \mathrm{~cm}$ mercury, capillary 10 , free drop-time $9 \pm 1 \mathrm{~s}$, controlled drop-time $0.5 \mathrm{~s}, m=0.86 \pm 0.03 \mathrm{mg} \mathrm{s}^{-1}$ ) gives $-I_{d} / c$ values which do not vary very much for wave II (except the $\mathrm{pH} 3.6$ formate value) but which can be very different for waves I, I' and mainly wave III:

Wave I $\quad 3.05 \leq-I_{d} / c \leq 3.85 \mu \mathrm{A} \mathrm{m} M^{-1}$

Wave $\mathrm{I}^{\prime} \quad 13.6 \leq-I_{d} / c \leq 29.2 \mu \mathrm{A} \mathrm{m} M^{-1}$

Wave II $-I_{d} / c=+1.20 \pm 0.15 \mu \mathrm{A} \mathrm{m} M^{-1}$

Wave III $\mathrm{pH}<8,3.1 \leq-I_{d} / c \leq 5.6 \mu \mathrm{A} \mathrm{m} M^{-1}$

$$
\mathrm{pH}>8,-\overline{I_{d}} / c=+1.20 \pm 0.15 \mu \mathrm{A} \mathrm{m} M^{-1}
$$

Fig. 5.

Diagram $I_{d} / c$ versus $\mathrm{pH}$ for the reduction of $10^{-4} M$ aqueous solutions of $\mathrm{N}_{1}$ methyl nicotinamide iodide by drop-time controlled polarography: (O) wave I,

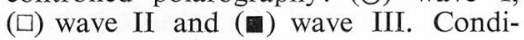
tions: capillary $10,35.0 \mathrm{~cm}$ mercury, controlled drop-time $0.5 \mathrm{~s}$, potential sweep rate $0.25 \mathrm{~V} / \mathrm{min}, m=0.86 \pm 0.03$ $\mathrm{mg} \mathrm{s}^{-1}$.

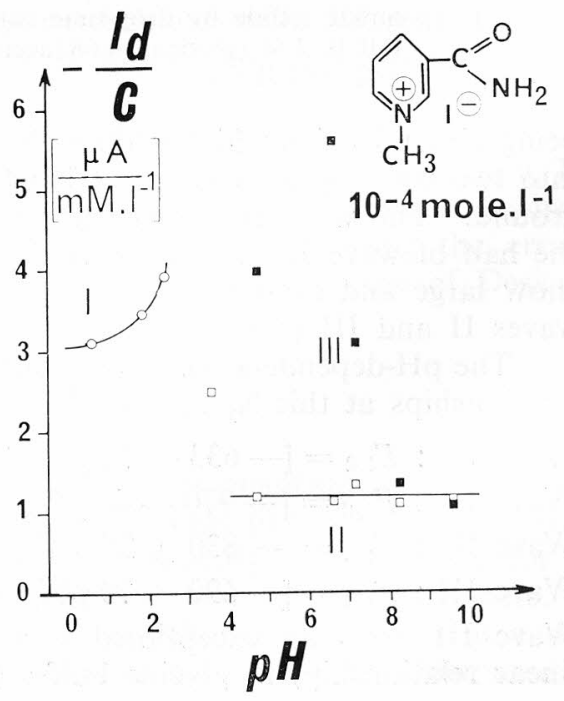




\section{Effect of buffer nature}

The abnormal 5.6 value for $-I_{d} / c$ of wave III in $10^{-4} M$ solutions was obtained with phosphate $(\mathrm{pH}$ 6.6) buffer: this illustrates perhaps a direct participation of orthophosphate ions in the electrochemical reaction. ALIVISATOS, et $a l .{ }^{27}$ presented experimental evidence for spontaneous reaction of NADH or similar compounds with dihydrogen phosphate and other "polybasic anions". PownING et al. ${ }^{14}$ and Kono et al. ${ }^{15}$ gave experimental data showing an enhancement of the formation of enzymatically active $\mathrm{NADH}$ by controlled potential electrolysis of $\mathrm{NAD}^{+}$at wave III potential if the buffer contains orthophosphate, pyrophosphate or tripolyphosphate ions. Except for wave $I^{\prime}$ which presents abnormal pattern and for wave III, linearity of the $E_{1 / 2}$ versus $\mathrm{pH}$ relationships and $-I_{d} / c$ versus $\mathrm{pH}$ relationships permits the assumption that the polarographic behaviour of $N_{1}$ methyl nicotinamide iodide in dilute aqueous solution does not depend on the buffer nature.

Voltammetric behaviour of $N_{1}$ methyl nicotinamide iodide in dilute aqueous solutions

Over the 6.6 to $9.9 \mathrm{pH}$ range $\mathrm{N}_{1}$ methyl nicotinamide iodide in dilute aqueous solution $\left(10^{-3} M\right)$ gives one reduction peak on stationary vitreous carbon electrode. The potential of this peak, measured at $0.5 \mathrm{~V} \mathrm{~s}^{-1}$ sweep rate (Fig. 6), is $\mathrm{pH}$-independent.

$$
\text { peak II : } E_{p}=-850 \pm 20 \mathrm{mV} \text { (N.H.E.) }
$$

Fig. 6.

Reduction of $10^{-3} \mathrm{M}$ aqueous solutions of $\mathrm{N}_{1}$ methyl nicotinamide iodide by ( $\square$ ) droptime controlled polarography and by (O) cyclic voltammetry on stationary vitreous carbon electrode at $0.5 \mathrm{~V} \mathrm{~s}^{-1}$ sweep rate. Reoxidation peak $($ ) observed by cyclic voltammetry on stationary vitreous carbon electrode at $0.5 \mathrm{~V} \mathrm{~s}^{-1}$ sweep rate when the scan is reversed at a potential below $-0.80 \mathrm{~V}$ (N.H.E.).

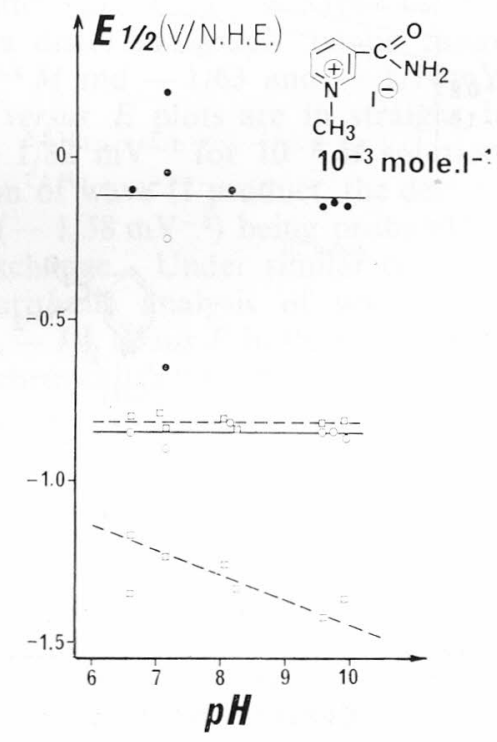


The mean peak potential value is $30 \mathrm{mV}$ lower than the $E_{1 / 2}$ of wave II: this result is consistent with the mechanism proposed for wave II (electronation followed by a dimerization of the radical) and with the nonintervention of the electrode material in this mechanism.

On return scan $\mathrm{N}_{1}$ methyl nicotinamide iodide gives an anodic peak whatever the sweep rate. This peak exist only when the lower potential range of the scan is below $-0.85 \mathrm{~V}$ (N.H.E.): it is the reoxidation peak of peak II reduction product. Except for the data obtained in imidazole $(\mathrm{pH}$ 7.1) buffer, the anodic peak potential is $\mathrm{pH}$-independent. Over the $\mathrm{pH}$ range 6.6 to 9.9 it lies at $-110 \pm 20 \mathrm{mV}$ (N.H.E.). The absence of any $\mathrm{pH}$ effect is consistent with a mechanism of reoxidation of a non-protonated reduction product i.e. the free radical or more probably its dimer. The reduction and reoxidation peaks having about the same area, the same number of electron should be exchanged in the two mechanisms, and the reoxidation should produce $\mathrm{N}_{1}$ methyl nicotinamide iodide back. If so, the norma potential of the system $\mathrm{N}_{1}$ methyl nicotinamide iodide - dimer should be situated at $-0.49 \mathrm{~V}$ (N.H.E.) whatever the $\mathrm{pH}$.

Effect of $N_{1}$ methyl nicotinamide iodide concentration on its polarographic behaviour in aqueous solution

Over the $\mathrm{pH}$ range 3.6 to $9.6 \mathrm{~N}_{1}$ methyl nicotinamide iodide reduction waves II and III shift when the compound concentration increases from $10^{-4}$ to $10^{-2} M$ (Fig. 7).

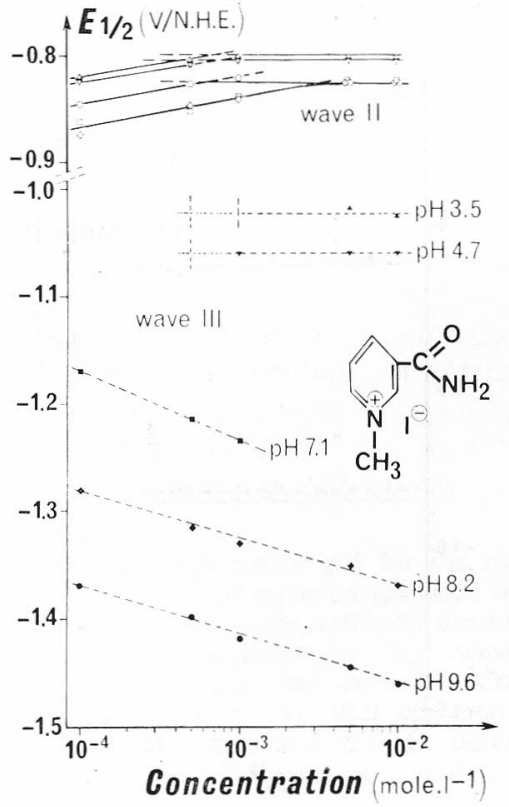

Fig. 7.

Effect of the concentration of $\mathrm{N}_{1}$ methyl nicotinamide iodide on its reduction waves position (-) wave II and (- - -) wave III. pH and buffer conditions: ( 3.56 formate, (v) 4.68 acetate, (1) 7.15 imidazole, (1) 8.25 tris and (•) 9.57 borate 


\section{Wave II}

The concentration dependence of wave II $E_{1 / 2}$ is different below or above the $10^{-3} M$ value. In diluite solutions $E_{1 / 2}$ shifts of $+20 \pm 2 \mathrm{mV}$ per concentration decade whereas in more concentrated solutions $E_{1 / 2}$ is constant. This behaviour is very similar to the behaviour of pyrimidine first reduction wave (wave I) in acid media. ${ }^{3}$

\section{Wave III}

The concentration dependence of wave III $E_{1 / 2}$ is different below and above $\mathrm{pH}$ 5. In formate and acetate buffer solutions $(\mathrm{pH} 3.56$ and 4.68 respectively $E_{1 / 2}$ is constant whereas in imidazole, tris and borate buffer solutions ( $\mathrm{pH} 7.15,8.25$ and 9.57 respectively) $E_{1 / 2}$ shifts of $-64,-45$ and $-45 \mathrm{mV}$ per concentration decade. In $\mathrm{pH} 7.15$ imidazole buffer wave III disappears in the background at concentration higher than $10^{-3} M$. A.s this buffer gives also an anomalous behavior in cyclic voltammetry on carbon electrode, we think that the two $-45 \mathrm{mV}$ per concentration decade are more significant.

The concentration dependence of the two reduction waves of $\mathrm{N}_{1}$ methyl nicotinamide iodide is similar to the electrochemical reduction behaviour of pyrimidine ${ }^{3}, \mathrm{~N}_{1}$ alkyl pyridinium salts ${ }^{28,29}$ and atomatic aldehydes and ketones ${ }^{30,31}$. These behaviors were interpreted as second-order interaction of the products of a reversible reduction ${ }^{32}$ and the mechanisms proved by a semilogarithmic plot of the two reduction waves: $\log \left[I^{2 / 3} /\left(I_{\text {lim }}-I\right)\right]$ versus $E$ for the first, $\log \left[I^{3 / 2} /\left(I_{\text {lim }}-I\right)\right]$ versus $E$ for the second. We tried the same way to plot classical $\log \left[I /\left(I_{\text {lim }}-I\right)\right]$ versus $E$ relation and one of the former relations with data obtained in $10^{-4}$ and $10^{--2} M$ solutions of $\mathrm{N}_{1}$ methyl nicotinamide iodide in borate buffer $(\mathrm{pH}$ 9.57). Whereas for wave II $\log \left[I /\left(I_{\text {lim }}-I\right)\right]$ versus $E$ plots form a distorted graph (slope ranging between $-1 / 53$ and $-1 / 61 \mathrm{mV}^{-1}$ for $10^{-4} M$ and $-1 / 63$ and $-1 / 74 \mathrm{mV}-1$ for $10^{-2} M$ solutions $), \log \left[I^{2 / 3} /\left(I_{l i m}-I\right)\right]$ versus $E$ plots are in straight line (slope $-1 / 68 \mathrm{mV}^{-1}$ for $10^{-4} M$ and $-1 / 82 \mathrm{mV}^{-1}$ for $10^{-2} M$ solutions). This may induce to suppose a dimerization of wave II product, the deviation from the theoretical value of the slope $\left(-1 / 58 \mathrm{mV}^{-1}\right)$ being probably due to some irreversibility of the electron exchange. Under similar conditions of $\mathrm{pH}$ and concentration, the semilogarithmic analysis of wave III i.e. $\log \left[I /\left(I_{\text {lim }}-I\right)\right]$ versus $E$ and $\log \left[I^{3 / 2} /\left(I_{\text {lim }}-I\right)\right]$ versus $E$ both give distorded graphs. This may induce other physico-chemical factors (adsorption on the electrode, chemical reaction with buffer...) occur during second step of the reduction.

\section{Conclusion}

Analysis of the literature data obtained for several pyridine nucleotides and model compounds shows the fundamental discrepancy between the resulis obtained with relatively fast voltammetric methods (polarography and cyclic voltammetry on mercury electrodes) and those obtaıned with slow 
potentiometric measurements. There is indeed at $\mathrm{pH} 7.0$ about $400 \mathrm{mV}$ difference both between the first reduction step potential of $\mathrm{NAD}^{+}$and the zero current potential of $\mathrm{NAD}^{+}-\mathrm{NADH}$ mixtures and between the latter and the first reoxidation potential of $\mathrm{NAD}^{+}$reduction product (Fig. 2). The zero-current potential has been always used by biochemists to explain the oxido-reduction role played by pyridine nucleotides. It seems that most important energetical and kinetical informations can be obtained from electrochemical studies of the oxicized and reduced forms.

Using $\mathrm{N}_{1}$ methyl nicotinamide iodide as model compound, we studied its reduction behavior by diop-time controlled polarography. In highly acidic media ( $\mathrm{pH}$ below 3 ) two $\mathrm{pH}$-dependent waves $\mathrm{I}$ and $\mathrm{I}^{\prime}$ were observed the second having an abnormally bigh limiting current. In acidic, neutral and basic media i.e. in the $\mathrm{pH}$ range 3 to 10 , two waves were observed, the former (wave II) being $\mathrm{pH}$-independent whereas $E_{1 / 2}$ of the latter (wave III) shifted of $-60 \mathrm{mV}$ per $\mathrm{pH}$ unit. Evidence is given of a chemical association step, possibly a dimerization, occurring between the two reduction steps II and III. Reoxidation of the wave II reduction product is obtained at $740 \mathrm{mV}$ above wave II potential by cyclic voltammetry on stationary vitreous carbon electrode. This reoxidation peak is $\mathrm{pH}$-independent as wave II.

Further investigations are presently conducted on the other reduction and oxidation steps of $\mathrm{N}_{1}$ methyl nicotinamide iodide in view to explain the difference between the reduction and oxidation potentials and mechanisms.

\section{References}

1 J.C. Bruice and S. Benkovic, Bioorganic Mechanisms, vol. 2, W.A. Benjamin, Inc. Amsterdam, New York, 1966.

2 D. THÉVENot, unpublished data (1970).

3 D. Thévenot and G. Hammouya, this volume p. 647.

4 C. Carruthers and J. Tech, Arch. Biochem. Biophys. 56, 441 (1955).

5 V. Moret, Giorn. Biochim. 4, 192 (1955).

$6 \quad$ F.L. Rodkey, J. Biol. Chem. 213, 777 (1955).

7 V. Moret, Giorn. Biochim. 5, 318 (1956).

$8 \quad$ B. KeE, Biochim. Biophys. Acta 20, 547 (1956).

9 J. NAKAYA, Nippon Kagaku Zasshi 81, 1459 (1960).

10 J. Bergman, in G.J. Hills ed., Proc. IIIrd Intern. Congress of Polarography, 1964, vol. $2, p .985$.

11 J.M. Burnett and A.L. Underwood, Biochemistry 4, 2060 (1965).

12 V.P. Skulachev and L.I. Denisovitch, Biokhimiya 31, 132 (1966).

13 A.J. Cunningham and A.L. Underwood, Biochemistry 6, 266 (1967).

14 R.F. Powning and C.C. Kratzing, Arch. Biochem. Biophys. 66, 249 (1951).

15 T. Kono and S. Nakamura, Bull. Agr. Chem. Soc. Japan 22, 399 (1958).

16 F.L. Rodkey and J.A. Donovan, J. Biol. Chem. 234, 677 (1959).

17 B. JANIK and P.J. Elving, Chem. Rev. 68, 295 (1968).

18 I. Yamazaki, K. Yokota and R. Nakajima, Biochem. Biophys. Res. Commun. 21, 582 (1965). 
A.J. Cunningham, Diss. Abstr. 27 B, 2265 (1967).

A.J. Cunningham and A.L. Underwood, Arch. Biochem. Biophys. 117, 88 (1966). J.N. Burnett and A.L. Underwood, J. Org. Chem. 30, 1154 (1965).

P. Karrer and F. Blumer, Helv. Chim. Acta 30, 1157 (1947).

P. Karrer, G. Schwarzenbach, F. Benz and U. Solmssen, Helv. Chim. Acta 19, 811 (1936).

E.J. Land and A.J. Swallow, Biochim. Biophys. Acta 162, 327 (1968).

W.J. Blaedel and R.G. HaAs, Anal. Chem. 42, 918 (1970).

S.J. Leach, J.H. Baxendale and M.G. Evans, Australian J. Chem. 6, 395 (1953).

S.G.A. Alivisatos, F. Ungar and G.J. Abraham, Biochemistry 4, 2616 (1966).

S.G. MaIranovskiI, Dokl. Akad. Nauk. S.S.S.R. 110, 593 (1956).

J. Volke, M. NaArová and V. Volkova, 21st. C.I.T.C.E. Meeting, Prag, 1970.

W. Kemúla, Z. Grabowski and M. Kalinowski, Naturwiss. 47, 514 (1960).

S.G. Mairanovskit and V.N. Pavlov, Zh. Fiz. Khim. 38, 1804 (1964).

S.G. Mairanovskit in P. Zuman, ed. Catalitic and Kinetic Waves in Polarography, Plenum Press, New York, 1968.

Handbook of Chemistry and Physics, The Chemical Rubber Co. Cleveland, Ohio, $1967 / 68$.

Handbook of Biochemistry, The Chemical Rubber Co., Cleveland, Ohio, 1968.

A. Albert, in A.R. Katrizky ed. Physical Methods in Heterocyclic Chemistry, vol. $1,1963$.

R.W. BuRnett and A.L. Underwood, Biochemistry 7, 3328 (1968). 